\title{
Association of Pulmonary Function with Waist Circumference (WC) and Body Mass Index (BMI) among the Students of Management \& Science University, Malaysia

\author{
Aniruddha Bhattacharjee*, Aye Aye Myat, Shakunthala VT and Rajeev Sharma
}

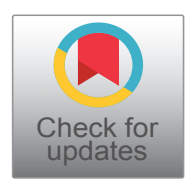

Department of Physiology, International Medical School, Management \& Science University (MSU), Malaysia

*Corresponding author: Dr. Aniruddha Bhattacharjee, Department of Physiology, International Medical School, Management \& Science University (MSU), Shah alam, Seksyen 13, Sealangor 40100, Malaysia

\begin{abstract}
Background: Obesity is rapidly escalating in Malaysia in all age groups. Prevalence of obesity and overweight is increasing in adults and in children in both developed and developing countries. Obesity is a risk factor for many conditions including respiratory disorders regardless of BMI. However, studies investigating pulmonary functions in obese adolescents in Malaysia are few. Hence, the present study was aimed to investigate pulmonary function variables in the adolescent obese students of management and science university (MSU) in Malaysia.
\end{abstract}

Aims: 1. To evaluate the effect of obesity on pulmonary function among adolescent students of MSU.

2. To identify the association between waist circumference (WC), body mass index(BMI) and waist hip ratio with pulmonary function among adolescent students of MSU.

Materials and methods: Dynamic lung functions were measured in 50 obese adolescent students of both sexes and an equal number of age-matched controls using Spirobank II MIR via Del Maggiolino125, 00155 Roma, Italy. Waist and hip circumference were measured using measuring tape.

Results: There was no significant difference in mean pulmonary function parameters between obese and nonobese control group. However, some of the obese subjects had mild restriction, whereas no obstructive impairment was detected in any subject of the obese and control groups.

$\mathrm{BMI}$, waist circumference and hip circumference has strong negative correlation with FEV1/FVC $(P<0.01)$, waist hip ratio was negatively correlated to FEV1/FVC but correlation was not significant. Waist circumference has strong positive significant correlation with FVC $(P<0.001)$, whereas waist hip ratio has no significant correlation with any pulmonary function parameters.
Conclusions: In conclusion, our study did not show a significant effect of obesity/overweight on dynamic lung volumes among adolescent of MSU. Significant negative correlation between $\mathrm{BMI}$, waist circumference and hip circumference with FEV1/FVC suggest that obesity decreases FEV1/FVC ratio and obese are more prone to obstructive lung diseases.

\section{Keywords}

Obesity, Pulmonary function test, Body mass index (BMI), Waist circumference, Hip circumference, Waist Hip ratio

\section{Introduction}

The lifestyle of students has changed in the past decades. Nowadays many of them have adopted unhealthy habits, like lack of exercise, intake of fast food that may impair their health [1]. Prevalence of obesity and overweight is increasing in adults and in children in both developed and developing countries [2,3]. Obesity is a risk factor for many conditions including respiratory disorders such as asthma, increased airway resistance and atopy $[4,5]$. Therefore, increasing numbers of obese children with respiratory disorders are referred for lung function testing.

The effects of obesity on pulmonary function parameters are influenced by the amount and distribution of body fat [6-8]. Studies have shown that central obesity, which may be measured by waist circumference or by waist-to-hip ratio, can influence respiratory mechanics regardless of $\mathrm{BMI}[6,8]$. Both $\mathrm{BMI}$ and $\mathrm{WC}$ are usual

Citation: Bhattacharjee A, Myat AA, Shakunthala VT, Sharma R (2019) Association of Pulmonary Function with Waist Circumference (WC) and Body Mass Index (BMI) among the Students of Management \& Science University, Malaysia. Int J Respir Pulm Med 6:110. doi.org/10.23937/2378-3516/1410110 Accepted: June 08, 2019; Published: June 10, 2019

Copyright: (C) 2019 Bhattacharjee A, et al. This is an open-access article distributed under the terms of the Creative Commons Attribution License, which permits unrestricted use, distribution, and reproduction in any medium, provided the original author and source are credited 
measures of overweight and obesity, but also indicators of body size, and they therefore may be associated with pulmonary function parameters such as forced expiratory volume in $1^{\text {st }}$ second $\left(\mathrm{FEV}_{1}\right)$ and forced vital capacity (FVC) $[9,10]$. However, studies investigating pulmonary functions in obese adolescent in Malaysia are few. Hence, the present study was aimed to investigate pulmonary function variables in the adolescent obese students of management and science university (MSU) in Malaysia.

\section{Aims \& Objectives}

1. To evaluate the effect of obesity on pulmonary function among adolescent of MSU.

2. To identify the association between waist circumference (WC) , body mass index (BMI) and waist hip ratio with pulmonary function among adolescent students of MSU.

\section{Subjects and Methods}

\section{Study design}

A cross-sectional comparative study has been conducted among the adolescent students of MSU.

\section{Ethical consideration}

Necessary ethical approval has been taken from the university ethical committee

\section{Study population}

MSU students of both sexes aged between 16 to 22 years were randomly selected for the study. Written consent was obtained from each participant.

Body mass index (BMI) of each subject was calculated as per the following formula:

Body mass index $=$ weight $($ kilograms $) /$ height $^{2}($ meter $^{2}$ ). Subjects having BMI greater than the $95^{\text {th }}$ percentile for age were classified as obese [11]. A total of 50 such obese boys were identified. An identical number of age-matched non-obese with $\mathrm{BMI}=18.50-24.99$ $\mathrm{kg} / \mathrm{m}^{2}$ were taken as controls. Subject with symptoms of illness like fever, cough, abdominal pain, etc., and anxious, apprehensive, and uncooperative ones were excluded from the study. All subjects were explained about the procedures to be undertaken. The following measurements/tests were performed.

\section{Anthropometric Measurements}

Weight (in kilograms) and height (in centimeters) were recorded on a beam balance. Waist circumference was measured as the smallest circumference between the ribs and the iliac crest to the nearest $0.1 \mathrm{~cm}$, while the participant was standing with the abdomen relaxed, at the end of normal expiration. Hip circumference was recorded as the maximum circumference between the iliac crest and the pubic symphysis.

\section{Pulmonary Function Testing}

The subjects were demonstrated the maneuvers of the pulmonary function tests. Computerized spirometry was carried out by using Spirobank II MIR, Del Maggiolino 125, 00155 Roma, Italy, observing the guidelines laid down by the American Thoracic Society and European Respiratory Society [12]. Calibration of the spirometer was carried out daily using a 3-L calibration syringe as recommended by the American Thoracic Society. For the FVC maneuver, the subjects were asked to take a deep inspiration and breathe out as rapidly as and as long as possible into the mouth piece of the spirometer. Flow volume curve was plotted with the best of three acceptable maneuvers being taken as the final reading. The following pulmonary functions were recorded: $\mathrm{FEV}_{1}$, FVC, $\mathrm{FEV}_{1} / \mathrm{FVC}$ (ratio of $\mathrm{FEV}_{1}$ and FVC), PEFR, $\mathrm{FEF}_{25-75 \%}$ or maximum mid-expiratory flow rate (MMEFR).

\section{Statistical Analysis}

The data of the obese and control groups were compared using Student's $t$-test. The following comparisons were made:

- BMI, Waist circumference, Hip circumference, waist/ hip ratio.

- Pulmonary function parameters of the obese and control groups.

Correlation co-efficient was calculated to determine the relationship between various measures of adiposity (BMI, waist circumference, hip circumference, and waist-to-hip ratio) and pulmonary function parameters.

Table 1: Characteristics of the 'obese/overweight' and 'normal weight' groups.

\begin{tabular}{|l|l|l|l|}
\hline & Obese $(\mathbf{n}=\mathbf{5 0})$ & Control $(\mathbf{n}=\mathbf{6 3})$ & P-value \\
\hline Age(yrs) & Mean (SD) & Mean (SD) & 0.79 \\
\hline Height(cm) & $19.85(1.35)$ & $19.96(1.59)$ & 0.14 \\
\hline Weight(kg) & $166.14(10.60)$ & $161.44(8.68)$ & 0.0002 \\
\hline Waist Circumference(cm) & $84.50(21.07)$ & $55.01(9.04)$ & 0.002 \\
\hline Hip Circumference(cm) & $92.43(18.52)$ & $74.43(7.16)$ & 0.0002 \\
\hline Waist hip ratio & $111.39(15.11)$ & $91.84(7.27)$ & 0.49 \\
\hline Body mass index $\left(\mathrm{kg} / \mathrm{m}^{2}\right)$ & $0.82(0.06)$ & $0.81(0.08)$ & 1.54 \\
\hline
\end{tabular}




\section{Results}

The general characteristics and anthropometric variables of the obese and control groups has been depicted in Table 1. Weight, Waist circumference, and hip circumference was found to be significantly higher in obese groups compared to control group. The comparison of pulmonary function parameters of the obese and control groups has been shown in Table 2 and Figure 1.

There was no significant difference in mean pul- monary function parameters between obese and nonobese control group. However, some of the obese subjects had mild restriction, whereas no obstructive impairment was detected in any subject of the obese and control group.

Table 3 presents the correlation matrix between various anthropometric variables and pulmonary function parameters. BMI has strong negative correlation with $\mathrm{FEV}_{1} / \mathrm{FVC}(\mathrm{P}<0.01)$, waist hip ratio was negatively correlated to $\mathrm{FEV}_{1} / \mathrm{FVC}$ but correlation is not signifi-

Table 2: Comparision of dynamic lung volumes among obese/overweight and normal weight group.

\begin{tabular}{|l|l|l|l|l|}
\hline Parameters & & Control(n= 50) & obese(n= 50) & P-values \\
\hline & & Mean (SD) & Mean (SD) & 0.39 \\
\hline FVC(L) & $(\mathrm{O})$ & $2.96(0.79)$ & $3.20(0.97)$ & 0.92 \\
\hline FEV1 (L) & $(\mathrm{P})$ & $85.23(14.55)$ & $85.84(17.66)$ & 0.49 \\
\hline FEV $/$ /FVC & $(\mathrm{O})$ & $2.83(0.73)$ & $3.01(0.85)$ & 0.86 \\
\hline & $(\mathrm{P})$ & $90.87(14.68)$ & $90.07(15.91)$ & 0.22 \\
\hline FEF & $(\mathrm{O})$ & $95.93(3.81)$ & $94.37(4.28)$ & 0.43 \\
\hline & $(\mathrm{P})$ & $106.28(4.48)$ & $105.21(4.5)$ & 0.62 \\
\hline PEFR(L/S) & $(\mathrm{O})$ & $4.52(1.20)$ & $4.36(1.06)$ & 0.33 \\
\hline & $(\mathrm{P})$ & $114.84(0.64)$ & $107.07(27.03)$ & 0.08 \\
\hline
\end{tabular}

$\mathrm{O}=$ Observed value; $\mathrm{P}=\%$ Predicted value .

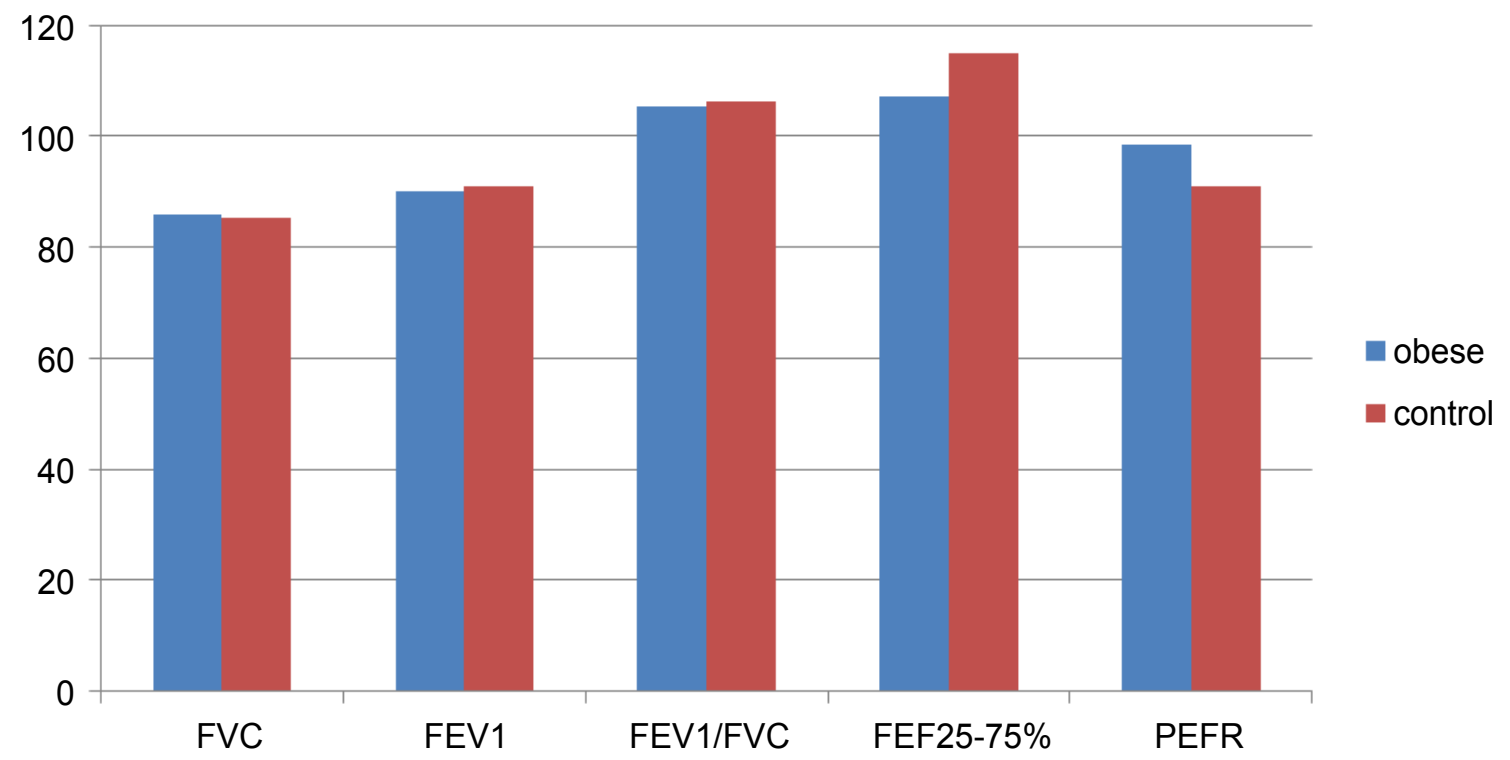

Figure 1: The comparison of pulmonary function parameters of the obese and control groups.

Table 3: Correlation of anthropometric parameters with various pulmonary function parameters in adolescent of MSU (values are correlation coefficient $r$ ).

\begin{tabular}{|l|l|l|l|l|l|}
\hline & FVC & FEV $_{\mathbf{1}}$ & FEV $_{\mathbf{1}}$ /FVC & FEF $_{25-75}$ & PEFR $^{*}$ \\
\hline BMI $\left(\mathrm{kg} / \mathrm{m}^{2}\right)$ & 0.2 & 0.15 & $-0.34^{* *}$ & -0.04 & 0.21 \\
\hline WHR & 0.26 & 0.27 & -0.06 & 0.08 & 0.24 \\
\hline Waist circumference & $0.36^{* *}$ & 0.32 & $-0.32^{* *}$ & 0.03 & 0.24 \\
\hline Hip Circumference & 0.25 & 0.2 & $-0.32^{* *}$ & -0.001 & 0.13 \\
\hline
\end{tabular}

" $p<0.05, " p<0.01, " * * 0<0.001$. 
cant. Waist circumference and hip circumference were strongly negatively correlated with $\mathrm{FEV}_{1} / \mathrm{FVC}(P<0.01)$. Waist circumference has very strong positive correlation with FVC, whereas waist hip ratio has no significant correlation with any pulmonary function parameter.

\section{Discussion}

\section{Effect of obesity on pulmonary function}

Some studies have shown a significant reduction in spirometry parameters with obesity while others have not shown any effect [13-15]. Turan and co-workers have shown in a comparative study on obese and non-obese that although there was no statistically significant difference in $\mathrm{FEV}_{1}, \mathrm{FVC}$, or $\mathrm{FEV} 1 / \mathrm{FVC}$, a significant reduction in peak expiratory flow rate (PEFR) and $\mathrm{FEF}_{25-75 \%}$ was found in overweight and obese individuals [13]. Our study did not find any significant effect of obesity or overweight on dynamic lung volumes measured by spirometer, however the mean FVC was high in obese compared to nonobese control group which may be due to higher body surface area of the subjects in obese group.

\section{Association of anthropometric parameter with pul- monary function}

In general, BMI is considered a measure of obesity and it cannot distinguish fat and lean body mass [16]. It is an index of nutritional status and its relationship with body composition is controversial. Waist circumference provides a simple measure of central fatness and it may have a direct effect on the chest wall properties. Waist Circumference mirrors body shape, while BMI provides an estimate of body mass and volume [17]. As previously shown, obesity is not a good parameter to evaluate body fat distribution when measured by BMI $[18,19]$. Abdominal obesity, measured by WC, was initially discussed as a risk factor for cardiovascular mortality and morbidity. Nowadays, other diseases are being studied to investigate the association with central obesity, including conditions related to pulmonary function [20]. One of the most discussed explanations in the literature is that abdominal fat may interfere in pulmonary mechanics, causing restrictions during breathing, potentially reducing respiratory volumes, such as $\mathrm{FEV}_{1}$ and FVC $[7,18,21]$. This mechanical effect is more evident if central obesity is considered instead of overall or peripheral fat [22]. The excess of fat in the abdomen and thoracic region may lead to decreases in the compliance and resistance of respiratory system, increasing energetic demands of breathing [21]. Another potential mechanism is that the increase in WC may have an effect on the diaphragm, limiting its movements [18]. There is no difference in the effect size on the respiratory system when different abdominal obesity indicators are used, such as WC and waist-to-hip ratio, and thoracic fat indicators [18], suggesting an interdependency of these measures with respect to pulmonary function parameters.
Our present study shows that BMI, waist circumference and hip circumference has strong negative correlation with $\mathrm{FEV}_{1} / \mathrm{FVC}(\mathrm{P}<0.01)$. A number of hypotheses have been proposed to explain the negative correlation between pulmonary function parameters and measures of visceral adiposity. One possible mechanism is a mechanical limitation of chest expansion during the FVC maneuver. Increased abdominal mass may impede the descent of the diaphragm and increase the thoracic pressure. Also, abdominal adiposity is likely to reduce ERV via compressing the lungs and diaphragm.

\section{Limitation of the study}

There are few limitations in our study. A bigger sample size would have given more concrete evidence. In our study we have only investigated the dynamic lung volumes since we did not have facilities to examine static lung volumes and ventilation-perfusion relationship in children.

\section{Conclusion}

In conclusions, our study did not show a significant effect of obesity/overweight on dynamic lung volumes among aldolescent of MSU. Significant negative correlation between BMI, waist circumference and hip circumference with $\mathrm{FEV}_{1} / \mathrm{FVC}$ suggest that obesity decreases $\mathrm{FEV}_{1} / \mathrm{FVC}$ ratio and obese are more prone to obstructive lung diseases.

\section{Conflict of Interest}

None.

\section{References}

1. US Department of Health and Human Services (2010) Healthy People 2020. Office of Disease Prevention and Health Promotion, New York.

2. Katulanda MA, Jayawardena MH, Sheriff GR, Constantine DR (2010) Prevalence of overweight and obesity in Sri Lankan adults. Obes Rev 11: 751-756.

3. World Health Organization (2000) Obesity: Preventing and managing the global epidemic: Report of a WHO consultation (WHO technical report series 894). The Office of Publication, Geneva.

4. Zammit C, Liddicoat $\mathrm{H}$, Moonsie I, Makker $\mathrm{H}$ (2010) Obesity and respiratory diseases. Int J Gen Med 3: 335-343.

5. Choudhary AK, Donnelly LF, Racadio JM, Strife JL (2007) Diseases associated with childhood obesity. Am J Roentgenol 188: 1118-1130.

6. Collins LC, Hoberty PD, Walker JF, Fletcher EC, Peiris AN (1995) The effect of body fat distribution on pulmonary function tests. Chest 107: 1298-1302.

7. Jubber AS (2004) Respiratory complications of obesity. Int $\mathrm{J}$ Clin Pract 58: 573-580.

8. Lazarus R, Sparrow D, Weiss ST (1997) Effects of obesity and fat distribution on ventilatory function: The normative aging study. Chest 111: 891-898.

9. Chen Y, Rennie D, Cormier YF, Dosman J (2007) Waist circumference is associated with pulmonary function in 
normal-weight, overweight, and obese subjects. Am J Clin Nutr 85: 35-39.

10. Chen Y, Rennie D, Cormier Y, Dosman JA (2009) Waist circumference associated with pulmonary function in children. Pediatr Pulmonol 44: 216-221.

11. Cole TJ, Bellini MC, Flegal KM, Dietz WH (2000) Establishing a standard definition for child overweight and obesity worldwide: International survey. BMJ 320: 1240-1246.

12. Miller MR, Hankinson J, Brusasco V, Burgos F, Casaburi R, et al. (2005) Series "ATS/ ERS task force: Standardization of lung function testing". Eur Respir J 26: 319-338.

13. Lazarus R, Colditz G, Berkey CS, Speizer FE (1997) Effects of body fat on ventilatory function in children and adolescents:Cross-sectional findings from a random population sample of school children. Pediatr Pulmonol 24: 187-194.

14. Torun E, Cakir E, Ozguç F, Ozgen IT (2014) The effect of obesity degree on childhood pulmonary function tests. Balkan Med J 31: 235-238.

15. Paralikar SJ, Kathrotia RG, Pathak NR, Jani MB (2012) Assessment of pulmonary functions in obese adolescent boys. Lung India 29: 236-240.

16. Wells JCK, Fewtrell MS (2006) Measuring body composition. Arch Dis Child 91: 612-617.
17. Klein S, Allison DB, Heymsfield SB, Kelley DE, Leibel RL, et al. (2007) Waist circumference and cardiometabolic risk: A consensus statement from shaping America's health: Association for weight management and obesity prevention; NAASO, the obesity society; the American society for nutrition; and the American diabetes association. Diabetes Care 30: 1647-1652.

18. Salome CM, King GG, Berend N (2010) Physiology of obesity and effects on lung function. J Appl Physiol 108: 206-211.

19. Bergman RN, Stefanovski D, Buchanan TA, Sumner AE, Reynolds JC, et al. (2011) A better index of body adiposity. Obesity (Silver Spring) 19: 1083-1089.

20. Leone N, Courbon D, Thomas F, Bean K, Jego B, et al. (2009) Lung function impairment and metabolic syndrome: the critical role of abdominal obesity. Am J Respir Crit Care Med 179: 509-516.

21. Piper AJ, Grunstein RR (2010) Big breathing: The complex interaction of obesity, hypoventilation, weight loss, and respiratory function. J Appl Physiol 108: 199-205.

22. Lazarus R, Gore CJ, Booth M, Owen N (1998) Effects of body composition and fat distribution on ventilatory function in adults. Am J Clin Nutr 68: 35-41. 